\title{
An ecological analysis of factors associated with food insecurity in South Australia, 2002-7
}

\author{
Wendy Foley ${ }^{1}$, Paul Ward ${ }^{1}$, Patricia Carter ${ }^{2}$, John Coveney ${ }^{1, *}$, George Tsourtos ${ }^{1}$ and \\ Anne Taylor ${ }^{3}$ \\ 'Department of Public Health, Flinders University, GPO Box 2100, Adelaide, South Australia 5001, Australia: \\ ${ }^{2}$ Health Promotion Branch, SA Health, Adelaide, South Australia, Australia: ${ }^{3}$ Population Research and Outcome \\ Studies Unit, SA Health, Adelaide, South Australia, Australia
}

Submitted 15 August 2008: Accepted 29 May 2009: First published online 26 August 2009

\begin{abstract}
Objective: To estimate the extent of food insecurity in South Australia and its relationship with a variety of socio-economic variables.

Design: Data collected routinely from 2002 to 2007 by SA Health were analysed to explore food security in the State's population. An ecological analysis of data collected by the South Australian Monitoring and Surveillance System (SAMSS) that collects data on key health indicators. Questions on food security are asked periodically from July 2002 to December 2007.

Setting: South Australia.

Subjects: Over 37000 interviewees took part in SAMSS surveys. Questions about food security were asked of 19037 subjects. The sample was weighted by area, age and gender so that the results were representative of the South Australian population.

Results: Seven per cent (1342/19037) of subjects reported running out of food during the previous year and not having enough money to buy food (food insecurity). Logistic regression analysis found food insecurity to be highest in households with low levels of education, limited capacity to save money, Aboriginal households, and households with three or more children.

Conclusions: The study confirms that food insecurity is strongly linked to economic disadvantage. Increasing cost of food is likely to exacerbate food insecurity. This is of concern given that food insecurity is associated with poor health, especially obesity and chronic disease. Comprehensive action at all levels is required to address root causes of food insecurity. Regular surveillance is required to continue to monitor levels of food security, but more in-depth understandings, via qualitative research, would be useful.
\end{abstract}



Keywords

Australia

Survey
As in many other countries, Australian consumers have recently had to accommodate increases in the cost of basic foods such as bread and other cereals, milk, meat, fruit and vegetables. From July 2007 to June 2008 the Consumer Price Index rose by $4 \cdot 5 \%$ - the largest annual change since 1995 , excluding the period associated with the introduction of a consumption tax (GST) in $2001^{(1)}$. During the financial year 2007-8, overall food prices rose by $3.9 \%$, while some basic food prices rose more sharply: cheese by $14 \cdot 2 \%$, milk by $12 \cdot 1 \%$, poultry by $11 \cdot 0 \%$ and bread by $6 \cdot 8 \%{ }^{(1)}$.

Food costs entered the political limelight prior to the Australian 2007 federal election, with voters demanding government action to reduce prices. To honour preelection promises, the newly elected Labour government initiated a national inquiry into grocery pricing soon after taking office. However, following the release of the grocery pricing inquiry report ${ }^{(2)}$ and the consequent launch of the government website to monitor prices ${ }^{(3)}$, critics consider there will be minimal if any impact on prices $^{(4,5)}$. This is partly because of international trends, where Australia is not immune from the global factors attributed to rising costs of basic foods ${ }^{(6)}$, and partly because the inquiry outcomes did nothing to actually address food costs.

Food cost plays a significant role in mediating food choice among low-income people ${ }^{(7,8)}$, who often have to cut back on food spending to make room for other essentials such as housing and utilities ${ }^{(9-12)}$, leading to decreased food security. To be food-secure means to have regular access to safe, nutritionally adequate, culturally acceptable food from non-emergency sources. Food insecurity, then, describes limited or uncertain ability to acquire appropriate foods in socially acceptable 
ways. This is not merely a lack of food; but also when people fear running out of food, or are forced to make significant changes to their usual eating patterns due to economic constraints ${ }^{(13)}$. Diets of food-insecure people have been shown to be of poor quality with lower levels of micronutrients ${ }^{(14-17)}$.

In Australia food security is defined both by the food supply (accessibility, affordability, availability of healthy food) and whether people have adequate resources and skills to acquire and use that food ${ }^{(18,19)}$. Food insecurity has not been readily acknowledged publicly in Australia and has been described as 'hidden' or 'silent' hunger ${ }^{(20)}$. Considered primarily a problem of the developing world, food security has only slowly appeared on government and civil society agenda in countries such as Australia. With the sharp rise in the proportion of Australians living below the poverty line over the past decade ${ }^{(21)}$, there is increasing concern about growing inequality and food insecurity ${ }^{(20,22)}$. Research about food security in vulnerable groups in Australia is emerging (e.g. references 19, 23 and 24) and health departments ${ }^{(14,25)}$ as well as some municipalities ${ }^{(26,27)}$ now have a sharpened focus on food security.

The prevalence of food insecurity in Australia has been variously estimated from $5 \cdot 2 \%$ for the whole population in the 1995 National Nutrition Survey ${ }^{(28)}$ to $71 \%$ among refugees resident in Australia for less than a year ${ }^{(23)}$, with figures ranging between these two numbers for other vulnerable groups ${ }^{(13,19,29)}$. Some Australians have come to accept moderate levels of food security due to lowpaid or insecure employment, illness, disability or Centrelink (government welfare agency) sanctions, and although they may be active in developing ways to cope with their situation, the particular vulnerabilities often lead to strategies that compromise the nutritional quality of diets ${ }^{(12)}$. However, having good access to healthy food is both a human right ${ }^{(30)}$ and an important determinant of health $^{(31-34)}$, with one study finding that food insecurity is also associated with compromised psychosocial functioning, such as increased likelihood of schoolchildren fighting with other children and having trouble with their teacher ${ }^{(33)}$. Even the least severe form of food insecurity is associated with higher body mass in adults ${ }^{(33,34)}$ as well as with type 2 diabetes ${ }^{(35)}$. Food insecurity has also been reported to be associated with depression ${ }^{(36,37)}$. A study conducted in the Lower Mississippi Delta region found that participants who resided in a food-insecure household rated significantly lower on SF-12 (Short Form 12item Health Survey) scores for both mental and physical health items ${ }^{(38)}$.

Since compromising diet is a common coping strategy in difficult financial times, particularly for those with the lowest incomes, and food insecurity-related health and social problems are considerable, monitoring food security in populations is an important public health strategy. There are no national or state data about food security published since the 1995 National Nutrition Survey and knowledge of current food security prevalence is therefore limited. The purpose of the current paper is to present recent data collected by the South Australian state health department (SA Health) on the prevalence and determinants of food insecurity in the State.

\section{Methods}

The data on which the present paper are based came from the South Australian Monitoring and Surveillance System (SAMSS). The SAMSS is a chronic disease and risk factor surveillance system operated by SA Health, which collects data to monitor key health indicators, including nutrition, from approximately 600 people of all ages each month using computer-assisted telephone interviewing technology. All households in South Australia with a telephone connected and the telephone number listed in the Electronic White Pages are eligible for selection in the sample. A letter introducing the survey is sent to selected households. The randomly selected households are telephoned and the householder with the most recent birthday is interviewed. If that person is less than 16 years of age, a parent or other appropriate adult provides answers on the child's behalf. There are no replacements for non-respondents. Up to ten call-backs are made to the household to interview the selected person. From July 2002 to December 2007 (the period on which the present paper is based), a total of 37976 interviews were conducted with an overall response rate of $70 \%$.

The data are weighted by area (metropolitan/rural), age, gender and probability of selection in the household compared with the most recent South Australian population data, so that the results are representative of the South Australian population. Of particular relevance to the present paper was the question asked in SAMSS to ascertain food security:

In the last twelve months, were there any times that the food you have bought just didn't last, and you didn't have money to get more?

This question was asked of respondents monthly from July 2002 until December 2003, from which time it was asked every 3 months for adults but monthly about children $(<16$ years). There are also other social, economic and demographic questions asked in the SAMSS, which were analysed for the purposes of the present paper.

\section{Data analyses}

Data were analysed using the SPSS statistical software package version $15 \cdot 0$ (SPSS Inc., Chicago, IL, USA). Bivariate analyses using logistic regressions were undertaken to analyse the associations between food insecurity during the previous year and a range of sociodemographic and health-related variables (see Table 2). 
All independent variables that were associated with food insecurity at the 0.25 level in each of the bivariate analyses were then entered into a multiple logistic regression analysis, using the block-enter method ${ }^{(39)}$. The final regression model was checked for collinearity. Overall, the final multiple regression model (Table 3) included only those variables that were statistically significant and added to the fit of the model.

\section{Results}

The results presented herein emanate from both the bivariate and multivariate analyses. Although we recognize that the multivariate odds ratios are usually used to provide independent associative factors, we present some of the bivariate associations (Table 2 gives a list of variables included in bivariate and multivariate analyses) because while some variables were significant only at the bivariate level, a number of these highlight particular vulnerabilities to food insecurity and are therefore important for public health nutrition. They also present areas for further research.

\section{Prevalence of food insecurity}

Overall, between July 2002 and December 2007, 7·0\% of people surveyed (1342/19037) reported running out of food during the previous year and not having money to buy more (food insecurity). This has fluctuated slightly, rising to $7.9 \%$ in 2004 and declining to $5.4 \%$ in 2007 (Fig. 1).

Table 1 shows the frequency of experiencing food insecurity among those people who reported food insecurity. While half reported experiencing food insecurity less than once a month during the previous year, for many other South Australians not having enough money for food was a more frequent occurrence.

\section{Indicators of food insecurity}

Bivariate logistic regression analysis was undertaken with all of the variables in Table 2 (with the food security variable as the dependent variable in all analyses), which were then all entered into a multiple logistic regression model. We do not provide specific details of each of the bivariate analyses since the multivariate analysis is more robust and useful in a policy context. However, we do provide an overview of the bivariate analyses in order to provide a potentially broader and richer picture for the reader.

Findings from the bivariate analyses revealed a statistically significant socio-economic gradient in the prevalence of food insecurity: those people with lower education, lower income, the unemployed and people living in households with limited capacity to save were more likely to be food-insecure, as were Aboriginal households, families with three or more children and people younger than 18 years of age. The strongest associations with food insecurity found in the bivariate analysis (odds ratio $>5)$ included: young people (0-17

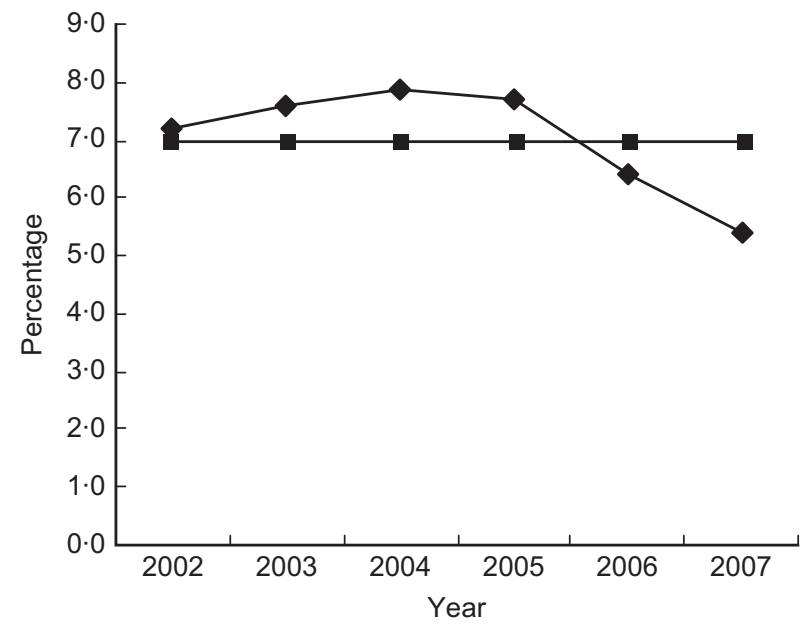

Fig. 1 Food insecurity prevalence (all ages) in South Australia, 2002 to 2007 (- - , annual prevalence; - - - , average)

Table 1 Frequency of experiencing food insecurity, South Australia, 2002-7

\begin{tabular}{lcc}
\hline $\begin{array}{l}\text { Frequency of running out of food and not having } \\
\text { money to buy more }\end{array}$ & & \\
\hline Less than once per month & $50 \cdot 7$ & 679 \\
1-3 times per month & $35 \cdot 2$ & 471 \\
4 or more times per month & $14 \cdot 1$ & 188 \\
\hline
\end{tabular}

years old), the unemployed, lower household income (less than \$AU 60001 ), household inability to save, renting from Housing SA and never feeling safe at home.

Table 3 shows the final multiple logistic regression model, which accounted for $31 \%$ of the variance (using the Nagelkerke test). The variables found to be the strongest predictors of food insecurity (odds ratio $>5$ ) were age less than 50 years, household income less than \$AU 20001 and household inability to save. Early adulthood (18-39 years) has a particularly high odds ratio $(>10)$. Variables that were entered but excluded from the equation included: marital status; household composition; have control over decisions affecting life; feel safe in home; safe neighbourhood; neighbours trust each other; SEIFA (Socio-Economic Indexes for Areas); and Aboriginality.

\section{Discussion}

\section{Prevalence of food insecurity}

While SAMSS data are weighted prior to analysis, the food insecurity prevalence of $7 \cdot 0 \%$ in South Australia over the studied time period is likely to be an underestimate for a number of reasons. The most vulnerable older people ${ }^{(14)}$ and people of lower socio-economic status, who are most likely to be food-insecure, have been found to participate less in surveys than those from higher socio-economic backgrounds ${ }^{(9,40,41)}$. Limited English language skills ${ }^{(41)}$ 
Table 2 Variables used in the bivariate logistic regression analysis, South Australian Monitoring and Surveillance System, 2002-7, all ages

\begin{tabular}{lcc}
\hline Sex & Capacity to save & Have control over decisions affecting life? \\
Female & Able to save & Agree \\
Male & Not able to save & Disagree \\
Age group (years) & Housing tenure & Feel safe in home \\
$\geq 70$ & Owned/being purchased & All the time \\
$60-69$ & Rented privately & Most of the time \\
$50-59$ & Rented from Housing SA & Some of the time \\
$40-49$ & Marital status & None of the time \\
$30-39$ & Married & Safe neighbourhood? \\
$18-29$ & Widowed & Yes \\
$0-17$ & De facto & No \\
Education & Never married & Neighbours trust each other? \\
Degree or higher & Separated & Yes \\
Trade, certificate, diploma & Divorced & No \\
No schooling to secondary & Household composition & SEIFAt \\
Work status & Partners with no children & Highest quintile \\
Full-time employed & Both biological parents with children & High quintile \\
Part-time employed & Related adults living together & Middle quintile \\
Economically inactive & Adult living alone & Low quintile \\
Unemployed & Unrelated adults living together & Lowest quintile \\
Household income & Step/blended & Aboriginality \\
$>\$ A U ~ 100000$ & Shared care parenting & Other \\
$\$ A U ~ 8001-100000$ & Sole parent & Aboriginal \\
$\$ A U 60001-80000$ & Children in the household & \\
$\$ A U ~ 40001-60000$ & 0 &
\end{tabular}

*Home duties, student, retired, unable to work.

tSocio-Economic Indexes for Areas.

and homelessness ${ }^{(9)}$, for example, preclude many people vulnerable to food insecurity from participating in telephone surveys. Moreover, telephone surveys in the USA have found lower prevalence rates of food insecurity than when the same questions were administered in face-toface interviews ${ }^{(42)}$. The telephone survey methodology used to collect the SAMSS data may similarly influence the food insecurity prevalence reported here. The question used to assess food security in the present research has also been shown to underestimate food insecurity. For example, when researchers compared the prevalence of food insecurity in disadvantaged areas in Sydney, derived from the single question commonly used in Australia, with a sixteen-item questionnaire used in $\mathrm{USA}^{(19)}$, the American tool yielded a higher prevalence $(21.9 \%)$ than the single question $(15 \cdot 8 \%)$. It also provided a more nuanced account of food insecurity in those communities, showing that $14 \%$ were food-insecure without hunger, $6 \cdot 1 \%$ with moderate hunger and $1.8 \%$ with severe hunger. As the single question used in the present study addresses only one dimension of food insecurity ${ }^{(14)}$, it cannot reflect the duration or severity of food insecurity experienced.

While the research instrument used to assess food insecurity prevalence gives a limited understanding of food insecurity in South Australia, it provides an indicator of food insecurity levels comparable with equivalent Australian studies ${ }^{(28)}$. Higher levels of food insecurity have been found in other developed nations. The 1997 New Zealand national nutrition survey found that $14 \%$ of people often or sometimes ran out of food in their household due to lack of money ${ }^{(43)}$. The question asked in the New Zealand survey was similar, though not identical, to that asked in SAMSS. In the USA in 2006, it was found from a series of eighteen food security questions that $10.9 \%$ of a nationally representative sample of households experienced food insecurity at least some time in the last year, with one-third of food-insecure households having very low food security ${ }^{(44)}$.

Despite uncertainties about exact numbers of foodinsecure people and the extent of food insecurity experienced, it is evident that too many South Australians have limited access to healthy food. In terms of actual numbers calculated from the State's estimated population at December $2007^{(45)}$, the number of South Australians likely to have experienced food insecurity in the previous year amounts to about 111500 people using the $7 \%$ average, but about 86014 using the $5 \cdot 4 \%$ figure for 2007 . It can thus be seen that a decrease in food insecurity prevalence of less than $2 \%$ impacts on a substantial number of people. Such a reduction would be expected to have a positive impact on the health and quality of life of those people.

\section{Social determinants of food insecurity}

Although some of the factors significantly associated with food insecurity in the bivariate analysis did not reach significance in the multivariate analysis, many have been shown to be associated with increased vulnerability to food insecurity in Australia. These include: unemployment; 
Table 3 Multivariate logistic regression analysis results, South Australian Monitoring and Surveillance System, 2002-7, all ages

\begin{tabular}{|c|c|c|c|}
\hline & \multicolumn{3}{|c|}{ Likelihood of food insecurity } \\
\hline & OR & $95 \% \mathrm{Cl}$ & $P$ value \\
\hline \multicolumn{4}{|l|}{ Sex } \\
\hline Male & $1 \cdot 00$ & ref & \\
\hline Female & $1 \cdot 17$ & $1 \cdot 02,1 \cdot 33$ & 0.03 \\
\hline \multicolumn{4}{|l|}{ Age group (years) } \\
\hline$\geq 70$ & $1 \cdot 00$ & ref & \\
\hline $60-69$ & $2 \cdot 04$ & $1 \cdot 19,3 \cdot 49$ & $<0.01$ \\
\hline $50-59$ & $4 \cdot 43$ & $2 \cdot 66,7 \cdot 38$ & $<0.01$ \\
\hline $40-49$ & $9 \cdot 15$ & $5 \cdot 58,15 \cdot 01$ & $<0.01$ \\
\hline $30-39$ & $10 \cdot 10$ & $6 \cdot 65,18 \cdot 17$ & $<0.01$ \\
\hline $18-29$ & $10 \cdot 73$ & $6 \cdot 52,17 \cdot 67$ & $<0.01$ \\
\hline $0-17$ & $8 \cdot 43$ & $5 \cdot 16,13 \cdot 78$ & $<0.01$ \\
\hline \multicolumn{4}{|l|}{ Education } \\
\hline Degree or higher & 1.00 & ref & \\
\hline No schooling to secondary & $1 \cdot 25$ & $1 \cdot 02,1 \cdot 52$ & 0.03 \\
\hline Trade, certificate, diploma & $1 \cdot 48$ & $1 \cdot 19,1 \cdot 84$ & $<0.01$ \\
\hline \multicolumn{4}{|l|}{ Work status } \\
\hline Full-time employed & $1 \cdot 00$ & ref & \\
\hline Part time employed & $1 \cdot 10$ & $0.91,1 \cdot 34$ & 0.33 \\
\hline Unemployed & $1 \cdot 02$ & $0 \cdot 71,1 \cdot 46$ & 0.92 \\
\hline Economically inactive & $1 \cdot 48$ & $1 \cdot 22,1 \cdot 80$ & $<0.01$ \\
\hline \multicolumn{4}{|l|}{ Household income } \\
\hline$>\$ A U 100000$ & $1 \cdot 00$ & ref & \\
\hline \$AU $80001-100000$ & 0.95 & $0 \cdot 56,1 \cdot 61$ & $0 \cdot 86$ \\
\hline \$AU $60001-80000$ & 1.59 & $1 \cdot 05,2 \cdot 40$ & 0.03 \\
\hline$\$ A U 40001-60000$ & $2 \cdot 89$ & $1 \cdot 96,4 \cdot 26$ & $<0.01$ \\
\hline \$AU $20001-40000$ & $4 \cdot 04$ & $2 \cdot 74,5 \cdot 97$ & $<0.01$ \\
\hline \$AU 12001-20000 & $5 \cdot 02$ & $3 \cdot 31,7 \cdot 61$ & $<0.01$ \\
\hline$\leq \$ A U 12000$ & $8 \cdot 80$ & $5 \cdot 51,14 \cdot 07$ & $<0.01$ \\
\hline \multicolumn{4}{|l|}{ Capacity to save } \\
\hline Able to save & $1 \cdot 00$ & ref & \\
\hline Not able to save & $6 \cdot 48$ & $5 \cdot 57,7 \cdot 53$ & $<0.01$ \\
\hline \multicolumn{4}{|l|}{ Housing tenure } \\
\hline Owned/being purchased & 1.00 & ref & \\
\hline Rented privately & $1 \cdot 65$ & $1 \cdot 39,1 \cdot 96$ & $<0.01$ \\
\hline Rented from Housing SA & $2 \cdot 20$ & $1 \cdot 74,2 \cdot 78$ & $<0.01$ \\
\hline \multicolumn{4}{|l|}{ Children in household } \\
\hline 0 & $1 \cdot 00$ & ref & \\
\hline $1-2$ & $1 \cdot 21$ & $0 \cdot 91,1 \cdot 61$ & $0 \cdot 18$ \\
\hline $3-10$ & $1 \cdot 64$ & $1 \cdot 20,2 \cdot 24$ & $<0.01$ \\
\hline
\end{tabular}

ref, referent category.

being divorced; being a single parent; being Aboriginal; living in the quintile of postcodes with the highest index of relative social disadvantage; not feeling safe at home; living in a neighbourhood perceived as unsafe; and having limited control over one's life $\mathrm{e}^{(9,13,14,28)}$.

The multivariate analysis presented several significant predictors of food insecurity, although a reduced number compared with the bivariate analyses due to the interaction effects between independent variables entered. Factors most strongly associated with food insecurity (odds ratio $>5$ ) include income less than \$AU 20 001, lack of capacity of the household to save and age $<50$ years. However, the odds of having been food-insecure in the previous year were at least twice as high for all age groups $<70$ years of age, those households with incomes of less than \$AU 60001 and those renting government housing.

The associations between food insecurity and low income or limited capacity to save are obvious. Links between economic disadvantage and food insecurity are well documented ${ }^{(9,14)}$ although the associations are complex $^{(13)}$ : not all disadvantaged people experience food insecurity and not all people who experience food insecurity are from low socio-economic backgrounds. If people do not have enough money, however, food selection is often compromised before housing and other essential expenses because food is often the sole discretionary item in household budgets for people with low incomes ${ }^{(9)}$. Low household income has been found to be associated with food insecurity in other Australian studies $^{(19,46)}$ as well as international studies ${ }^{(11,43,47,48)}$. Incapacity to save money has also been found to be significantly associated with food insecurity in Sydney households in disadvantaged neighbourhoods ${ }^{(19)}$ and among older people ${ }^{(49)}$. Indeed, the odds of food insecurity were very similar for households in the present study and households in Sydney that reported they could not manage to save money ${ }^{(19)}$. That housing tenure is associated with food security in the present study was to be expected from similar findings in other studies ${ }^{(12,19,49)}$ and the fact that people are selected to rent government housing based on their economic circumstances.

Younger people in South Australia reported food insecurity more than did older people. This equates with findings from Sydney ${ }^{(19)}$ as well as from the 1997 New Zealand nutrition survey which found a significant increasing linear trend of food security with age ${ }^{(43)}$. This is of particular concern as adolescence is an important time for growth where food needs are higher during than other periods. A study of older Australians in New South Wales found that among people 65 years and older, only $2 \%$ reported food insecurity in the previous year ${ }^{(49)}$. This finding is very similar to those herein.

The lack of a statistically significant association between food insecurity and unemployment in the multivatiate analysis may be caused by the employment category including those with insecure or low-paying employment, which can limit the capacity to purchase food of sufficiently good quality ${ }^{(13)}$. As a result, low income and limited capacity to save proved to be more effective indicators of food insecurity than unemployment in the present study.

\section{Conclusions}

Food is a powerful marker of social inclusion or exclusion $^{(50)}$ and the extent of food insecurity in the community is indicative of inequality and poverty. The widening inequalities in Australia $^{(21)}$ provide cause for concern about food insecurity among the most socio-economically disadvantaged. It is clear that many people in South Australia face the problem of not being able to access adequate food at some time in their lives and that the burden of food insecurity falls disproportionately on 
lower socio-economic groups and younger people. Rose delineates the importance of looking at recent economic changes when trying to understand food insecurity ${ }^{(51)}$. With the rapidly increasing costs across a spectrum of competing household needs experienced in Australia in 2008 , and the resultant stress on household budgets ${ }^{(1)}$, it is probable that the downward trend in food security prevalence indicated by the SAMSS data may not continue. Disadvantaged sectors of society are likely to experience the greatest hardship.

Food insecurity has its roots in systemic structural inequalities and has a high cost to individuals, families and society ${ }^{(9)}$. As food insecurity is associated with poor health, and in particular obesity and chronic disease ${ }^{(52)}$ which take a high toll on the health of Australians and also on health expenditure, it is imperative that policies and programmes be developed to improve food security in the population. Comprehensive action is needed to address the complex issues causing food insecurity ${ }^{(9)}$. Importantly, political will to facilitate an equitable food system and access to food is needed. While typical food security support focuses on individuals (e.g. emergency food handouts), it would be more effective to address food insecurity at its systemic roots, as recommended by the Commission on Social Determinants of Health ${ }^{(32,53)}$. Indeed, the final report of the Commission ${ }^{(32)}$ cites the lack of access to healthy food as a social determinant of health, recommending the establishment of 'food security policies' and government regulation to 'encourage healthy eating through retail planning to manage the availability of and access to food' (p. 66). In addition, the fact that many of the predictor variables in our analyses are likely to 'cluster' in particular geographical localities makes it even more important to target interventions based on place, rather than just individual risk. Analyses such as ours could be extended in order to produce a 'social atlas of food security' which would allow such targeting to take place.

Given these factors, it is important to continue to monitor food insecurity in South Australia. Further, to appropriately address food insecurity, it is important to develop a more nuanced understanding of food insecurity, as Booth and Smith indicated in 2001 when they argued for more information on the degree of food insecurity in the population than can be obtained with the single question used in the present study ${ }^{(9)}$. Further qualitative and quantitative research is required to really understand and therefore better address food insecurity experienced in South Australia.

\section{Acknowledgements}

This research was funded by SA Health under the Strategic Health Research Priorities programme. The authors declare that they have no conflict of interest regarding the study. W.F. contributed to data analysis and writing;
P.W. contributed to conception and design of the study, analysis advice and writing; P.C. contributed to writing; J.C. contributed to conception and design of the study and writing; G.T. contributed to analysis advice and writing; A.T. contributed to analysis advice and writing. Data were analysed at the Population Research and Outcome Studies (PROS) Unit, SA Health. Thanks to staff at the PROS Unit for assistance with data analysis, particularly Jodie Avery and Tiffany Gill.

\section{References}

1. Australian Bureau of Statistics (2008) Consumer price index Australia: June quarter 2008. http://www.ausstats.abs. gov.au/ausstats/subscriber.nsf/0/8D94183E5AB6CA19CA 25748E0012B013/\$File/64010_jun\%202008.pdf (accessed July 2008).

2. Commonwealth of Australia (2008) Report of the ACCC Inquiry into the Competitiveness of Retail Prices for Standard Groceries. Canberra: Australian Competition and Consumer Commission.

3. Commonwealth of Australia (2008) GROCERYchoice. http:// www.grocerychoice.gov.au/ (accessed August 2008).

4. Get Farming Australia (2008) Government in a spin while Australian retailing comes up trumps - Retail response to ACCC Grocery Prices Inquiry 2008. http://www.getfarming.com.au/ pages/farming/articles_view.php?fId=9200020080808141316 (accessed September 2008).

5. Irvine J (2008) Rudd price check: he's powerless. Sydney Morning Herald, 6 August.

6. Stoeckel A (2008) High Food Prices: Causes, Implications and Solutions. Canberra: Rural Industries Research and Development Corporation.

7. Turrell G \& Kavanagh AM (2006) Socio-economic pathways to diet: modelling the association between socioeconomic position and food purchasing behaviour. Public Health Nutr 9, 375-383.

8. Harrison MS, Coyne T, Lee AJ \& Leonard D (2007) The increasing cost of the basic foods required to promote health in Queensland. Med J Aust 186, 9-14.

9. Booth S \& Smith A (2001) Food security and poverty in Australia - challenges for dietitians. Aust J Nutr Diet 58, $150-156$

10. Wrigley N, Warm D, Margetts B \& Lowe M (2004) The Leeds 'food deserts' intervention study: what the focus groups reveal. Int J Retail Distrib Manag 32, 123-136.

11. Kirkpatrick S \& Tarasuk V (2007) Adequacy of food spending is related to housing expenditures among lower-income Canadian households. Public Health Nutr 10, 1464-1473.

12. Douglas J (2006) Food insecurity in northern Adelaide. SACOSS News, Chapter 8. Adelaide: SACOSS.

13. Burns C (2004) A Review of the Literature Describing the Link between Poverty, Food Insecurity and Obesity with Specific Reference to Australia. Victoria: VicHealth.

14. NSW Centre for Public Health Nutrition (2003) Food Security Options Paper: A Planning Framework and Menu of Options for Policy and Practice Interventions. Sydney: NSW Department of Health \& The University of Sydney.

15. Champagne CM, Casey PH, Connell CL et al.; Lower Mississippi Delta Nutrition Intervention Research Initiative (2007) Poverty and food intake in rural America: diet quality is lower in food insecure adults in the Mississippi Delta. J Am Diet Assoc 107, 1886-1894.

16. Tarasuk V, McIntyre L \& Li J (2007) Low-income women's dietary intakes are sensitive to the depletion of household resources in one month. J Nutr 137, 1980-1987. 
17. Hamelin AM, Beaudry M \& Habicht JP (2002) Characterization of household food insecurity in Quebec: food and feelings. Soc Sci Med 54, 119-132.

18. Carter P \& Taylor A (2007) Food insecurity in South Australia. Public Health Bull South Aust 4, 23-25.

19. Nolan M, Rikard-Bell G, Mohsin M \& Williams M (2006) Food insecurity in three socially disadvantaged localities in Sydney, Australia. Health Promot J Aust 17, 247-254.

20. Wilson J (1997) Australia: lucky country/hungry silence. In First World Hunger: Food Security and Welfare Politics, pp. 14-45 [G Riches, editor]. Basingstoke: St. Martin's Press.

21. Saunders P \& Davidson P (2007) Rising poverty is bad for our health. Med J Aust 187, 530-531.

22. Engels B (2006) The funding and provision of emergency relief in Australia. In Thinking About Poverty, pp. 169-198 [K Serr, editor]. Sydney: Federation Press.

23. Gallegos D, Ellies P \& Wright J (2008) Still there's no food! Food insecurity in a refugee population in Perth, Western Australia. Nutr Diet 65, 78-83.

24. Bryce A, Donoghue C, Allen B \& Stokes S (2005) Food security and permanent residents of caravan parks. Environ Health 25, 73-83.

25. VicHealth (2005) Healthy Eating - Food Security Investment Plan 2005-2010. Melbourne: VicHealth.

26. VicHealth (2003) Food for All? Food Insecurity Community Demonstration Projects: Maribyrnong City Council and North Yarra Community Health Case Studies. Melbourne: VicHealth.

27. South Sydney City Council Food Policy Committee (1995) What's Eating South Sydney: A Policy for a Safe, Affordable and Nutritious Food Supply in South Sydney. Sydney: South Sydney City Council Food Policy Committee.

28. Marks GC, Rutishauser IH, Webb DK \& Picton P (2001) Key Food and Nutrition Data for Australia 1990-1999. Canberra: Australian Food and Nutrition Monitoring Unit.

29. Maddern R (1994) National Aboriginal and Torres Strait Islander Survey 1994: Detailed Findings. Canberra: Australian Bureau of Statistics.

30. United Nations General Assembly (1948) Universal Declaration of Human Rights, Resolution 217 A (III) of 10 December 1948. New York: UN.

31. Vozoris NT \& Tarasuk VS (2003) Household food insufficiency is associated with poorer health. J Nutr 133, 120-126.

32. Commission on Social Determinants of Health (2008) Closing the Gap in a Generation: Health Equity Through Action on the Social Determinants of Health. Final Report of the Commission on Social Determinants of Health. Geneva: WHO.

33. Olson CM (1999) Nutrition and health outcomes associated with food insecurity and hunger. J Nutr 129, 2S Suppl., 521S-524S

34. Townsend MS, Peerson J, Love B, Achterberg C \& Murphy SP (2001) Food insecurity is positively related to overweight in women. J Nutr 131, 1738-1745.

35. Seligman HK, Bindman AB, Vittinghoff E \& Kushel MB (2007) Food insecurity is associated with diabetes mellitus: results from the National Health Examination and Nutrition Examination Survey (NHANES) 1999-2002. J Gen Intern Med 22, 1018-1023.

36. Kim K \& Frongillo EA (2007) Participation in food assistance programs modifies the relation of food insecurity with weight and depression in elders. J Nutr 137, 1005-1010.
37. Bronte-Tinkew J, Zaslow M, Capps R, Horowitz A \& McNamara M (2007) Food insecurity works through depression, parenting, and infant feeding to influence overweight and health in toddlers. J Nutr 137, 2160-2165.

38. Stuff J, Casey P, Szeto K, Gossett J, Robbins J, Simpson P, Connell C \& Bogle ML (2004) Household food insecurity is associated with adult health status. J Nutr 134, 2330-2335.

39. Hosmer D \& Lemeshow S (editors) (2000) Model building strategies and methods for logistic regression. In Applied Logistic Regression, 2nd ed., pp. 95-116. New York: John Wiley and Sons.

40. King T, Kavanagh AM, Jolley D, Turrell G \& Crawford D (2006) Weight and place: a multilevel cross-sectional survey of area-level social disadvantage and overweight/ obesity in Australia. Int J Obes (Lond) 30, 281-287.

41. Turrell G, Patterson C, Oldenburg B, Gould T \& Roy M-A (2003) The socio-economic patterning of survey participation and non-response error in a multilevel study of food purchasing behaviour: area- and individual-level characteristics. Public Health Nutr 6, 181-189.

42. Nord M \& Hopwood H (2007) Does interview mode matter for food security measurement? Telephone versus inperson interviews in the current population survey food security supplement. Public Health Nutr 10, 1474-1480.

43. Parnell WR, Reid J, Wilson NC, McKenzie J \& Russell DG (2004) Food security: is New Zealand a land of plenty? $N Z$ Med J 114, 141-145.

44. Nord M, Andrews M \& Carlson S (2007) Household Food Security in the United States, 2006. Washington, DC: US Department of Agriculture; available at http://www.ers. usda.gov/Publications/ERR49/ERR49.pdf

45. Australian Bureau of Statistics (2008) Population, Australian States and Territories, December 2007. Canberra: Commonwealth of Australia.

46. Radimer K, Allsopp R, Harvey P, Firman D \& Watson E (1997) Food insufficiency in Queensland. Aust N Z J Public Health 21, 303-310.

47. Dowler E (2003) Food and poverty: insights from the 'north'. Dev Policy Rev 21, 569-580.

48. Hadley C, Zodhiates A \& Sellena DW (2007) Acculturation, economics and food insecurity among refugees resettled in the USA: a case study of West African refugees. Public Health Nutr 10, 405-412.

49. Quine S \& Morrell S (2006) Food insecurity in communitydwelling older Australians. Public Health Nutr 9, 219-224.

50. Wood B, Swinburn B \& Burns C (2003) Eating Well in Victoria, Food Security for All: Executive Summary. Multisite Evaluation Final Report. Melbourne: Deakin University, Victorian Health Promotion Foundation \& Victorian Department of Human Services Public Health Division.

51. Rose D (1999) Economic determinants and dietary consequences of food insecurity in the United States. $J$ Nutr 129, 517-520.

52. Robertson A, Tirado C, Lobstein T, Jermini M, Knai C, Jensen JH, Ferro-Luzzi A \& James WPT (editors) (2004) Food and Health in Europe: A New Basis for Action. Geneva: WHO.

53. Priority Public Health Conditions Knowledge Network (2007) Inequities in the Health and Nutrition of Children. Report of the Priority Public Health Conditions Knowledge Network of the Commission on Social Determinants of Health. Geneva: WHO. 